\title{
Thymol quantitative analysis in medicinal formulation types through employing of nano-technology and antimicrobial activity in some pathogenic bacterial isolates
}

\author{
MOHAMMED HASAN BARRAK ${ }^{1}$, MOHAUMAN MOHAMMAD AL-RUFAIE, ${ }^{1, \bullet}$, ZAHRAA YOSIF MOTAWEQ ${ }^{2}$ \\ ${ }^{1}$ Department of Chemistry, Faculty of Science, Kufa University. Najaf, Iraq. `email: mohaumanmajeed@yahoo.com, muhaimin.alrufaie@uokufa.edu.iq \\ ${ }^{2}$ Department of Biology, Faculty of Science, Kufa University. Najaf, Iraq \\ Manuscript received: 25 April 2021. Revision accepted: 30 May 2021.
}

\begin{abstract}
Barrak MH, AL-Rufaie MM, Motaweq ZY. 2021. Thymol quantitative analysis in medicinal formulation types through employing nano-technology and antimicrobial activity in some pathogenic bacterial isolates. Nusantara Bioscience 13: 129-137. This study included a method for estimating thymol (THY) in its pure state and in some of its pharmaceutical preparations that were quick, easy, and sensitive, This method is based on nanoparticles that have been modified by oxidation and reduction reactions, In a sodium hydroxide base medium, with polyvinylpyrrolidone as a stabilizer. The thymol drug works as a reducing agent to dilute the ore mineral salt from silver nitrate $\left(\mathrm{Ag}^{+}\right)$to silver nanoparticles; the oxidation-reduction reaction product for thymol has the highest absorption at $410 \mathrm{~nm}$. The calibration curve was calculated, and the following information was determined, indicating that the Beer-Lambert Law was followed within the focus range of 0.25 to 50 parts per million. Sandal's sensitivity was $0.052 \mu \mathrm{g} / \mathrm{cm}^{2}$, his molar absorptivity was 2.2883 $\mathrm{x} 10^{3} \mathrm{~L} / \mathrm{mol} . \mathrm{cm}$, his standard deviation rate was $0.402 \%$, and his correlation coefficient was 0.9989 . The biological effect on a number of Gram-negative and Gram-positive bacteria was studied, and the findings showed that the samples prepared were effective against these bacteria.
\end{abstract}

Keywords: Bacterial, formulation, medicinal, nano-technology, pathogenic, quantitative, thymol

\section{INTRODUCTION}

Pharmacologically classified as 2-isopropyl-5-methyl phenol is crystalline in colorless form monoterpene phenol, it has been used in traditional medicine and has been shown to have different pharmaceutical characteristics including antibacterial, antioxidant, antispasmodic, free radical scavenging, analgesic, antifungal, anti-inflammatory, antitumor activity and antiseptic, thymol (THY) possesses pharmacological properties and its numerous therapeutic activities biochemical and molecular diseases contra specific diseases: neurological, cardiovascular, metabolic, malignant, rheumatologic and gastrointestinal, the notable thymol influences are primarily due to it is antiinflammatory activity (by stitching cytokine and chemokine recruitment).

Antioxidant (by free radical scavenging, enhancing enzymatic additionally non-enzymatic antioxidants, as well as metal chelation ions), antihyperlipidemic effects (through elevated rates of high-density lipoprotein cholesterol as well as lower amounts of low-density lipoprotein cholesterol in circulation as well as membrane stabling) (through Ionic Homeostasis maintenance) (Meeran et al. 2017) Figure 1.

Thymol (THY) was previously estimated by (Chromatographic (LC) with Electrochemical Detection) (Gao et al. 2010), (Chromatographic HPLC) (Hajimehdipoor et al. 2010), (Ultrasound) (Roosta et al. 2015), (Chromatographic GC-MS) (Jiménez-Salcedo and
Tena 2017), (Chromatographic HPLC-UV) (Angelo et al. 2016), (Chromatographic GC-MS with HS-SPME) (Fiori et al. 2013), (Voltammetric) (Ziyatdinova et al. 2017), (Electrochemical) (Aghamohseni et al. 2019), (Spectrophotometric) (Dhahir and Hussein 2012), (Spectrophotometric Batch and Flow Injection) (Al-Ward and Al-Abachi 2012).<smiles>Cc1ccc(C(C)C)c(O)c1</smiles>

Figure 1. Chemical structure of thymol

Table 1. The pharmaceutical preparations that were studied

\begin{tabular}{lll}
\hline $\begin{array}{c}\text { Drug Formulations } \\
\text { samples }\end{array}$ & \multicolumn{1}{c}{$\begin{array}{c}\text { Declared } \\
\text { composition }\end{array}$} & \multicolumn{1}{c}{ Company } \\
\hline Listerine antiseptic Fresh & $\begin{array}{l}\text { Per } 0.064 \% \\
\text { thymol }\end{array}$ & $\begin{array}{l}\text { ADA, American } \\
\text { dental association }\end{array}$ \\
Burst wash mouth & Per $0.064 \%$ & ADA, American \\
Listerine antiseptic cool & thymol & dental association \\
mint wash mouth & Per $0.12 \%$ & Zak \\
Zak Mouth and Dental & thymol & Egypt \\
wash $240 \mathrm{~mL}$ & & \\
\hline
\end{tabular}




\section{MATERIALS AND METHODS}

\section{Materials and reagents}

All of the substances used in this study were inexpensive and of the highest purity, and they were used without further disinfection throughout, the $0.01 \mathrm{M} \mathrm{AgNO}_{3}$ solution was generated by dissolving $0.4246 \mathrm{~g}$ in deionized water in a $250 \mathrm{~mL}$ volumetric vial with a standardized solution, Sodium hydroxide $0.001 \mathrm{M}$ was made by dissolving $0.0199 \mathrm{~g}$ in $500 \mathrm{~mL}$ deionized water, and a Polyvinylpyrrolidone $(0.2 \%)$ solution was made by breaking down $0.2 \mathrm{~g}$ in deionized water in a $100 \mathrm{~mL}$ volumetric vial, and completed to the mark in all volumetric vials, They were from the same company, reagent grade $\mathrm{BDH}$, and they were delivered together, thymol was prepared as a $250 \mathrm{ppm}$ standard and used solution by breaking down $25 \mathrm{mg}$ of bulk drug in $100 \mathrm{~mL}$ water collected from SDI (State Drug Industries and Medical Appliances Company) (Iraq), the studied technique was applied to thymol using three different types of drug formulations, These types are illustrated in Table 1.

\section{Collection and diagnosis of bacterial isolates}

Multidrug-resistant (MDR) pathogenic bacterial isolates include: From stool, burns, wounds, synovial fluids, blood, and urine, two gram-negative bacteria (Klebsiella pneumoniae and Escherichia coli) were isolated, while two gram-positive bacteria (Enterococcus faecalis and Staphylococcus aureus) were isolated (Olurinola 1996; MacFaddin 2009; Deepthi and Narasimha 2013; Vu et al. 2018; Kavitha et al. 2019).

All bacterial isolates were stored on BHI broth supplemented with $(15 \%)$ glycerol at $\left(-20^{\circ} \mathrm{C}\right)$ and later confirmed using an automated bacterial recognition instrument Vitek-2 compact system GP additionally GN card. Before use, the isolates were sub-cultured on BHIA and incubated at $37{ }^{\circ} \mathrm{C}$ for 24 hours, in the laboratories of the Biology Department of the College of Science at the University of Kufa.

\section{Chemical samples for application were prepared as follows:}

Test tube 1: polyvinylpirrolidone $1 \mathrm{~mL}$, sodium hydroxide $0.5 \mathrm{~mL}$, thymol $1 \mathrm{~mL}$, then dilution by distilled water to $9.3 \mathrm{~mL}$, then Silver nitrate $0.7 \mathrm{~mL}$.

Test tube 2: polyvinylpirrolidone $1 \mathrm{~mL}$, sodium hydroxide $0.5 \mathrm{~mL}$, then dilution by distilled water to 9.3 $\mathrm{mL}$, then Silver nitrate $0.7 \mathrm{~mL}$.

Test tube 3: Thymol $1 \mathrm{~mL}$, then dilution by distilled water to the signal $10 \mathrm{~mL}$.

Test tube 4: Silver nitrate $0.7 \mathrm{~mL}$ then dilution through deionized water to the signal $10 \mathrm{~mL}$.

\section{Antibacterial activity experimental}

The bacterial suspensions were prepared according to Ramalivhana et al. (2014) explained. The antibacterial activity of test tubes was compared to bacterial isolates using the agar well diffusion method (Murray et al. 1995; Kavitha et al. 2019). The test tubes were compared to bacterial isolates in MHA medium to see how biologically active they were.

\section{Agar well diffusion assay}

The micropipette was used to distribute $100 \mu \mathrm{L}$ of bacterial suspensions BHIB on the surfaces of the MHA plate, and wells were punctured in all of the culture plates using a sterile cork borer. One well was a perforation in the middle of the plate, with $100 \mu \mathrm{L}$ Gentamicin added as a positive control; another well had $100 \mu \mathrm{L}$ (DMSO) added as a negative control, and the residual wells had $100 \mu \mathrm{L}$ test tubes alone. The cultivation plates were then incubated for 24 hours at $37^{\circ} \mathrm{C}$. In millimeters, the clear inhibition zone around wells has been measured. The experiments were carried out in three different ways (Olurinola 1996).

\section{Apparatus}

The main equipment used in this research includes: (i) T80 UV-Visible Spectrophotometer. PG Instruments Ltd. (Double beam). (ii) 303 PD UV-Visible Spectrophotometer. Apel. Japan (Single beam). (iii) UV-1650PC UVVisible Spectrophotometer, SHIMADZU. Japan (Double beam). (iii) Electric Balance. Matter Toledo. Switzerland. (iv) Shaking water bath, Model: vs-1205 wl. scientific Co. Ltd. (v) pH meter, Spinbot thephaw.

\section{Procedure for calibration curve}

In volumetric flasks with a capacity of $10 \mathrm{~mL}, 0.2 \%$ PVP was added The sodium hydroxide solution was then added to these volumetric flasks in a volume of $0.5 \mathrm{~mL}$, then, in these volumetric flasks, different volumes of thymol were added, ranging from $(0.01 \mathrm{~mL}$ to $3 \mathrm{~mL})$, and then dilution to $9.3 \mathrm{~mL}$ with distilled water then $0.7 \mathrm{~mL}$ of silver nitrate $(0.01 \mathrm{M})$ in each volumetric flask, after 40 minutes at $35^{\circ} \mathrm{C}$, the absorbance of each solution was measured at $410 \mathrm{~nm}$ against a reagent blank.

\section{Zak mouth and dental wash}

A sample of $240 \mathrm{~mL}$ mouth and teeth wash and the proportion of thymol in it $(0.12 \% \mathrm{C}), 21 \mathrm{~mL}$ of it was taken and placed in a volume volumetric flask $100 \mathrm{~mL}$, then diluted with distilled water to a mark, Then, in thymol measurements, take different volumes and treat them in the same way as before.

\section{Listerine antiseptic cool mint wash mouth}

A sample of $250 \mathrm{~mL}$ Cool mint wash mouth and the proportion of thymol in it $(0.064 \% \mathrm{C}), 39 \mathrm{~mL}$ of it was taken and placed in a volume volumetric flask $100 \mathrm{~mL}$, then diluted with distilled water to a mark, Then after, different volumes are taken and treated in a previous manner for thymol measurements.

\section{Listerine antiseptic fresh burst wash mouth}

A sample of $250 \mathrm{~mL}$ Fresh Burst wash mouth and the proportion of thymol in it $(0.064 \% \mathrm{C}), 39 \mathrm{~mL}$ of it was taken and placed in a volume volumetric flask $100 \mathrm{~mL}$, then diluted with distilled water to a mark, then, in thymol measurements, different volumes are taken and treated in the same way. 


\section{RESULTS AND DISCUSSION}

\section{Absorption spectra}

When the Colorless thymol solution (C), Blank (B) (PVP, $\mathrm{NaOH}$, Distilled water for dilution and $\mathrm{AgNO}_{3}$ ) colorless solution and (A) sample of (PVP, $\mathrm{NaOH}$, thymol, Distilled water for dilution and $\mathrm{AgNO}_{3}$ ), the red-colored product, as well as the reactants, are scanned in a UV-VIS spectrophotometer to emphasize the reaction

Figure $2 \mathrm{~A}, \mathrm{~B}$, and $\mathrm{C}$ show the spectra of the aqueous solution of pure thymol in the spectral region of 190-800 $\mathrm{nm}$, blank solution and colored product ( the prepared on addition PVP then $\mathrm{NaOH}$ then thymol then Distilled water for dilution and $\mathrm{AgNO}_{3}$ ), the red product with maximum absorption of $410 \mathrm{~nm}$ differs significantly from the maximum absorption of both reactants, as shown in this figure. The usefulness of this redshift for a product can be used as a thymol assay procedure.

\section{Optimization of reaction conditions}

\section{Effect of different silver nitrate volumes}

The effect of different silver nitrate volumes required to achieve optimum absorbance is investigated; the experiment is carried out with $\mathrm{AgNO}_{3}(0.01 \mathrm{M})$ volumes ranging from $0.1 \mathrm{~mL}$ to $2 \mathrm{~mL}$, Figure 3 , when $1.5 \mathrm{~mL}$ of silver nitrate $(0.01 \mathrm{M})$ is added, the maximum absorbance is reached, so this method uses $0.7 \mathrm{~mL}$ of silver nitrate $(0.01 \mathrm{M})$.

\section{Effect of polyvinylpirrolidone in different volumes}

The effects of different polymers (Polyvinylpirrolidone PVP, Polyurethane PU, and Polyvinyl chloride PVC) on color product formation were investigated, $1 \mathrm{~mL}$ of $(0.2 \%)$ concentration was added to see if the polymers used had any effect on the formation of thymol, PVP proved to be the most absorbent polymer for the color solution. The best volume of the base form was then determined, the effects of various volumes of PVP $(0.1,0.3,0.5,0.7,1, \ldots$, and 2 $\mathrm{mL}$ ) on the formation of thymol.

Figure 4, when $0.1 \mathrm{~mL}$ is added, the maximum absorbance is reached. As a result, $1 \mathrm{~mL}$ of Polyvinylpyrrolidone $(0.2 \%)$ is used in this method, we selected PVP as a stabilizer for preventing of silver nanoparticles agglomeration, the $\mathrm{H}+$ ions are produced in the silver nitrate reaction by analyses. As a result, removing $\mathrm{H}+$ will promote Ag-NP formation. When adding PVP to the solution, It helps in the stabilization of silver ions by forming Ag (PVP)+ complexes and removing $\mathrm{H}+$ produced by $\mathrm{H}(\mathrm{PVP})+$ during the oxidation process (Nezhad et al. 2010).

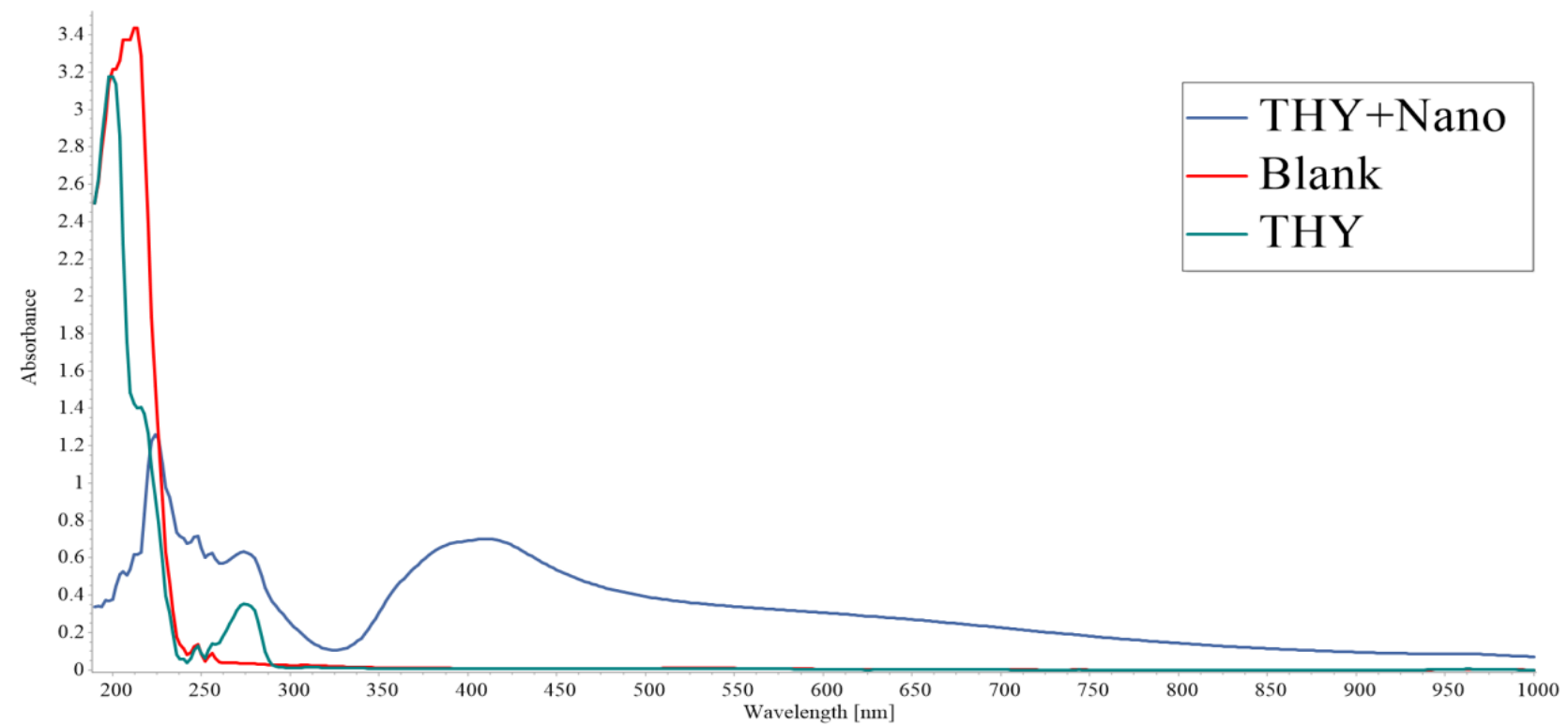

Figure 2. Sample (Sliver Nano withthymol antibiotic (A), Blank (All reagents without antibioticthymol (B), and thymol Pure (C) in the Absorption Spectrum. 


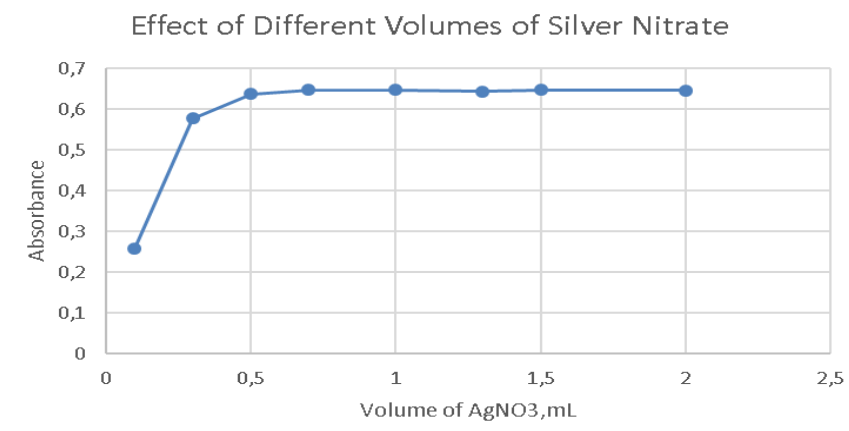

Figure 3. Effect of Silver nitrate

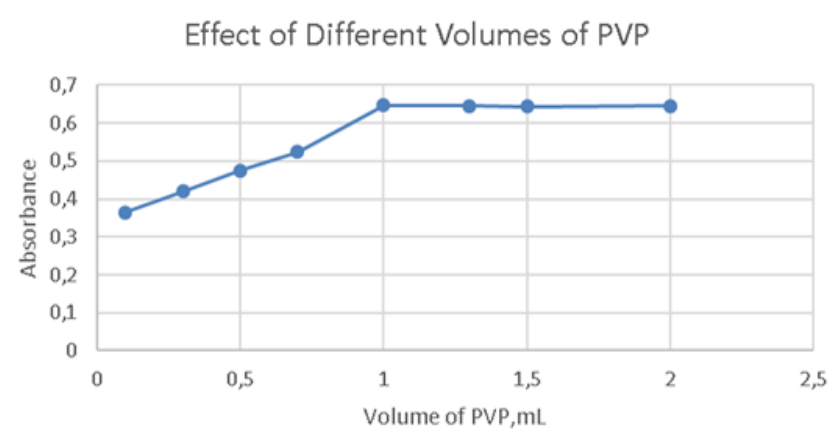

Figure 4. Effect of Polyvinylpyrrolidone

Table 2. The Sequence of Addition effect

\begin{tabular}{ccccc}
\hline Sequence & $\mathbf{A}+\mathbf{B}+\mathbf{C}+\mathbf{D}+\mathbf{E}$ & $\mathbf{C}+\mathbf{B}+\mathbf{A}+\mathbf{D}+\mathbf{E}$ & $\mathbf{C}+\mathbf{E}+\mathbf{B}+\mathbf{D}+\mathbf{A}$ & $\mathbf{E}+\mathbf{C}+\mathbf{B}+\mathbf{D}+\mathbf{A}$ \\
\hline Absorbance & 0.600 & 0.594 & 0.525 & 0.579 \\
\hline
\end{tabular}

\section{Effect of different volumes Base}

The effects of different bases $\left(\mathrm{NaOH}, \mathrm{KOH}, \mathrm{NH}_{4} \mathrm{OH}\right.$, and $\mathrm{Na}_{2} \mathrm{CO}_{3}$ ) on colour product formation were studied. 1 $\mathrm{mL}$ of $(0.001 \mathrm{M})$ concentration was added to see how the bases affected the formation of the product thymol, $\mathrm{NaOH}$ was the perfect base for the color solution because it had a high absorbance. after determining the best volume of the base type Different volumes of $\mathrm{NaOH}$ were used to determine their effects on the formation of thymol: $0.1,0.3$, $0.5,0.7,1, \ldots$, and $3 \mathrm{~mL}$, respectively, Figure 5 , when $2 \mathrm{~mL}$ of sodium hydroxide $(0.001 \mathrm{M})$ is added, the maximum absorbance is reached; therefore, $0.5 \mathrm{~mL}$ of sodium hydroxide $(0.001 \mathrm{M})$ is used for this method, when the elimination of $\mathrm{H}+$ may help in the formation of Ag-NPs, the effect of the solution's alkalinity on the reaction was investigated by varying the $\mathrm{NaOH}$ concentration, as seen, the peak strength of the silver nanoparticles signal increases by the increasing concentration of $\mathrm{NaOH}$ additionally then decreases, this decrease may be due to the $\mathrm{Ag}_{2} \mathrm{O}$ formation. Consequently, a $0.2 \mathrm{mM} \mathrm{NaOH}$ concentration was identified as the optimal level for further studies (Nezhad et al. 2010).

\section{Sequence of addition}

The sequence in which the solutions are added in the reactions that produce the silver nanoparticles under investigation has a significant impact on the color intensity of the resulting compounds, therefore several experiments were conducted with a sequence of different additions and for all the studied interactions to choose the best addition sequence that gives the highest absorption of the resulting compounds as shown in Table 2.

It is found from Tables 3-7 that the order of addition of reagents is by mixing PVP, then Sodium hydroxide, then thymol, then dilute with distilled water to $8.7 \mathrm{~mL}$, then Silver nitrate $(A+B+C+D+E)$ giving the highest absorbance, this sequence gives the best formation of the product.
The best addition sequence for all silver nanoparticle reactions was found to be $(\mathrm{A}+\mathrm{B}+\mathrm{C}+\mathrm{D}+\mathrm{E})$ in Table 2 , so it was used in subsequent experiments.

\section{Temperature effect on colored product formed}

The effect of temperature on the speed at which silver nanoparticles form was examined, with a temperature range of $25-75^{\circ} \mathrm{C}$ used, as shown in Figure 6, Stability in absorption has been found as absorbance increases with increasing temperature up to a $35^{\circ} \mathrm{C}$. This can be due to the probability of stability in the formation of silver nanoparticles.

As a result, the preferred temperature for the formation of Silver nanoparticles was $35^{\circ} \mathrm{C}$. In subsequent experiments with silver nanoparticle interactions, these temperatures were chosen.

\section{Time effect on colored product formed}

The effect of time on the formation of silver nanoparticles has been investigated, and under the best conditions that have been proven in previous experiments, for periods of time ranging from 10-120 minutes, with measurements taken every ten minutes, the resulting nanoparticle has high stability of more than one hour or more, allowing these interactions to be examined easily. Figure 7 indicates that, as a result, a development period of 40 minutes is chosen as the optimum in the general method.

\section{The effect of time on the colored product formed after 72 hours}

Time effect on the velocity of formation of nanoparticles was studied 72 hours after the velocity formation of nanoparticles was constant at 0.801 absorptions.

\section{Calibration curve}

The standard calibration curve for the colored product has been created under the optimum conditions discussed in Figure 8. 


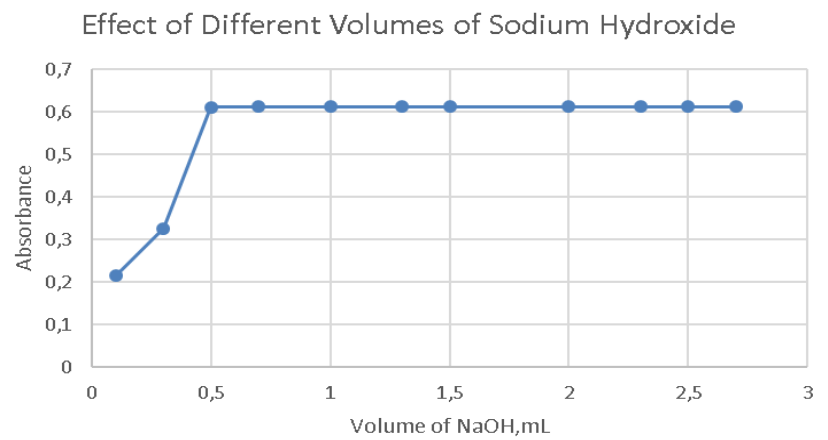

Figure 5. Effect of Different Volumes Sodium hydroxide

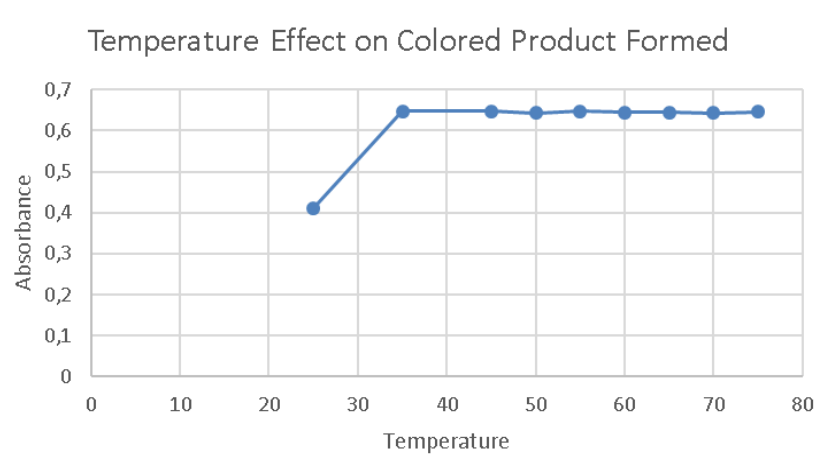

Figure 6. Effect of temperature on colored product

Other analytical parameters are calculated, and the results are shown in Table 3 show that this analytical method performs well for determining thymol at low concentrations.

\section{Precision and accuracy}

Precision first was measured using nine replicates at $2.5,25$, and $37.5 \mu \mathrm{g} / \mathrm{mL}$ thymol concentrations to check the precision and accuracy of the proposed method.

The accuracy of three specific thymol concentrations is calculated, and the results are shown in Table 4 indicate that the thymol determination method is accurate and satisfactory (Tawa and Shingo 1980).

\section{Mechanism of the product}

As shown in Figures 9 and 10, the mechanism of reaction may indicate a connection between the drugs under examination and the reagents used in their estimation.

\section{Interferences effect}

In order to ensure that method is selective, it was tested on a variety of samples, particularly pharmaceutical preparations containing the pharmaceutical thymol, the relationship of excipients (interferes) was studied, as it was achieved by conducting a spectral estimation of the estimated pharmacological compounds and adding these substances separately to the studied solutions, and these substances become ten times more concentrated than the studied drug compound, and using the same approach used

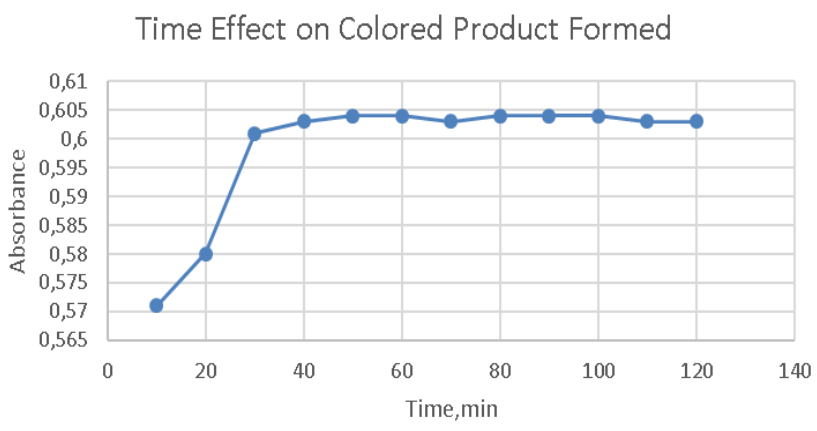

Figure 7. Time Effect on Colored Product Formed

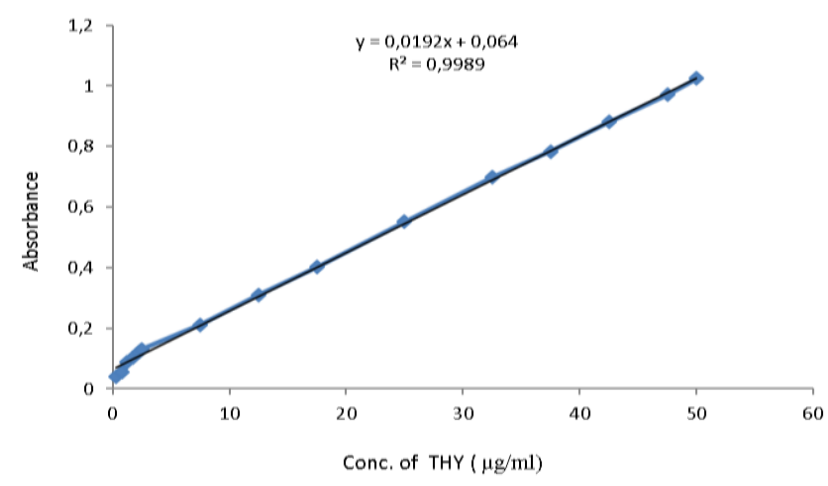

Figure 8. Calibration curve of thymol

in the calibration curve, PVP, then sodium hydroxide, then $1 \mathrm{~mL}$ from (250 ppm) of the drug, then distilled water, then silver nitrate, then $1 \mathrm{~mL}$ from concentration $(2500 \mathrm{ppm})$ of each additive, applying the rest of the best conditions and measuring the absorbance of the product, calculating the error and recovery ratio, taking into consideration consider the dilution of the resulting solution to $25 \mathrm{~mL}$ with distilled water, the interference effects are acceptable if the error ratio does not exceed (2\%). when compared to measurements without overlaps (Ahmed and Shahla 2019), (Each value is a three-reading average). We can see that the existence of additives has no effect on the thymol estimation methods by looking at the values of (percent Error) and (Recovery percent), the existence of additives had an effect on the absorption of the colored compound, as shown in Table 5, Notice the effect of such additives on the thymol estimation process by pursuing values of percent error and percent recovery.

Table 3. Analytical Parameter for Determining thymol

\begin{tabular}{lc}
\hline \multicolumn{1}{c}{ Parameter } & Value \\
\hline beer's law limit (ppm) & $0.25-50$ \\
Molar Absorptivity $(\mathrm{L} / \mathrm{mol} . \mathrm{cm})$ & $2.2883 \times 10^{3}$ \\
Correlation Coefficient & 0.9989 \\
Limit of Quantitation $(\mathrm{LOQ}) \mathrm{ppm}$ & 0.3682 \\
Sandell's sensitivity $(\mu \mathrm{g} / \mathrm{cm} 2)$ & 0.052 \\
Limit of Detection $(\mathrm{LOD}) \mathrm{ppm}$ & 0.1104 \\
Determination Coefficient & 0.9994 \\
Intercept $(\mathrm{a})$ & 0.0640 \\
Slope $(b)$ & 0.0192 \\
\hline
\end{tabular}


Table 4. Value Accuracy and Precision for the product compound of thymol

\begin{tabular}{|c|c|c|c|c|}
\hline \multicolumn{2}{|c|}{ Concentration of thymol (ppm) } & \multirow{2}{*}{ Relative \% error } & \multirow{2}{*}{$\%$ Recovery } & \multirow{2}{*}{ \% R.S.D } \\
\hline Percent & Found & & & \\
\hline 2.5 & 2.440 & -2.400 & 97.600 & 0.900 \\
\hline 25 & 25.360 & 1.440 & 101.440 & 0.181 \\
\hline 37.5 & 37.440 & -0.160 & 99.840 & 0.127 \\
\hline
\end{tabular}

Table 5. The effect of the presence of additives at a concentration of ( $25 \mathrm{ppm})$ on the absorbance of the compound thymol

\begin{tabular}{lcc}
\hline \multicolumn{1}{c}{ Interference } & \% Error & \% Recovery \\
\hline lactose & -1.780 & 98.220 \\
Talc & -0.955 & 99.045 \\
starch & 0.995 & 100.995 \\
Acacia & 0.546 & 100.546 \\
Sucrose & -1.245 & 98.755 \\
Glucose & 1.274 & 101.274 \\
magnesium citrate & -0.170 & 99.830 \\
Benzoic acid & -0.887 & 99.113 \\
aspartame & 0.430 & 100.430 \\
Mannitol & -0.661 & 99.339 \\
Cross povidone & 0.740 & 100.740 \\
Twin 80 & 0.395 & 100.395 \\
Titanium dioxide & -0.570 & 99.430 \\
Microcrystal cellulose & -1.150 & 98.850 \\
Sucrose & 0.120 & 100.120 \\
\hline
\end{tabular}

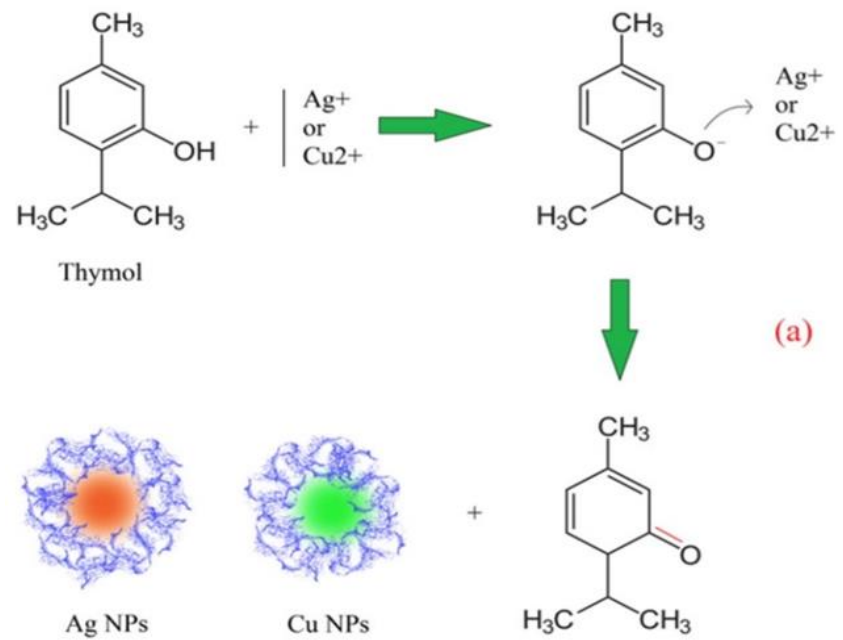

Figure 9. Probable mechanism of reduction in silver and ions by thymol (Alavi and Naser 2019).

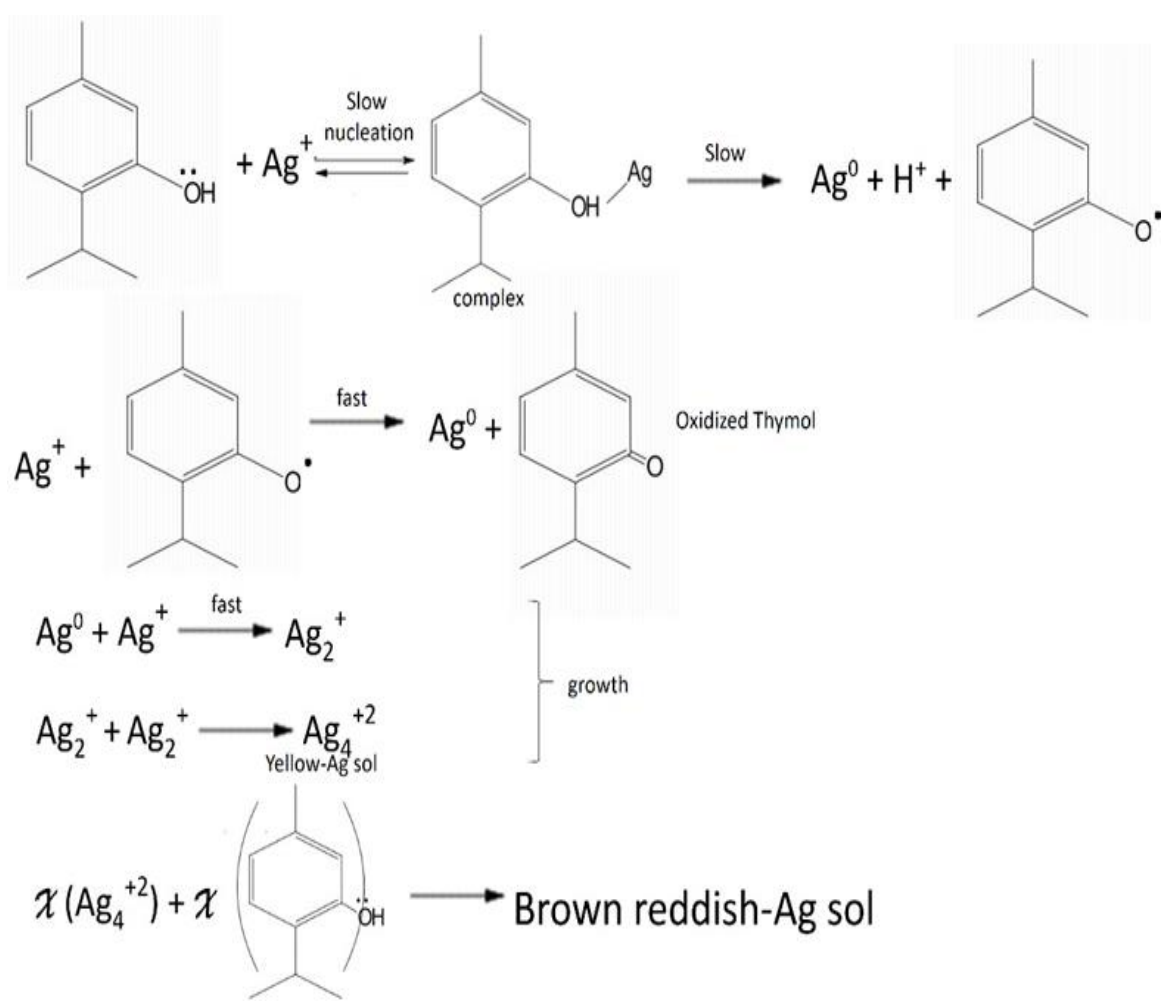

Figure 10. Mechanism of the generation of AgNPs at room temperature (Ganash 2019) 


\section{Application of the methods}

To see if the methods proposed are effective, A number of pharmaceutical formulations containing thymol in pharmaceutical solutions had to be added according to the methods used, and a diluted solution had to be prepared (250 ppm), take three different volumes of each solution that was prepared, and apply the steps used to prepare the calibration curve, then calculate the accuracy of the analytical method used with these prepared solutions and all of the studied reactions is compatible with the results obtained for a variety of pharmaceutical preparations, show the effectiveness and success of the proposed method in applying to pharmaceutical preparations, as shown in Table 6 . Each value in the table is the average of three readings, and to compare the effectiveness and success of proposed analytical methods with the results of a well-known and reliable method (found within the British and American pharmaceutical industries) of substance pure drug and its various forms of pharmaceutical preparations available on the market, the measured results for $\mathrm{F}$ and $\mathrm{T}$ are 9.28 and 2.45, respectively (Harvey 2000; Christian 2004; Moffat et al. 2011), we could see that the measured value is less than the theoretical value, indicating that the method is reliable.

\section{Biological activity}

Nanoparticles Antibacterial activity and antibiotics were tested against known human pathogens using a disk diffusion assay, and antibiotics with NPs showed a larger inhibition zone than antibiotics and NPs alone, this demonstrates the possibility of nanoparticles and antibiotics working together in a synergistic manner Bhosale et al. (2015) as in the following Table 7.

Silver nanoparticles were also studied on their own or in conjunction with antibiotics, with the findings indicating that they had antibacterial effects and synergistic activity (Hwang et al. 2012), the study centered on the susceptibility of microorganisms to silver nanoparticles, antibiotics, and their combined effects; when nanoparticles and antibiotics were given together, the diameter of the inhibition zone increased by a minimum of 2 to $4 \mathrm{~mm}$ (Geoprincy et al. 2014; Nikparast and Mahsa 2018) the dose-dependent capacity of AgNPs to inhibit the activity of biofilms produced by human pathogens identified under in vitro conditions is used to inhibit biofilm growth. According to these results, biologically synthesized AgNPs inhibited biofilm activity in all of the bacterial strains studied Gurunathan et al. (2014) as in the following Figures $11-14$.

Table 6. F, $\mathrm{t}$ compare the accuracy and reliability of the proposed process with the standard nanoparticles composition reaction method Between thymol and silver ion nanoparticles (Moffat et al. 2011)

\begin{tabular}{|c|c|c|c|c|c|c|c|c|}
\hline \multirow{3}{*}{$\begin{array}{l}\text { Preparation thymol } \\
\text { Containing }\end{array}$} & \multicolumn{4}{|c|}{ Deliberated process } & \multicolumn{4}{|c|}{ Official process } \\
\hline & \multicolumn{2}{|c|}{ Conc. of thymol (ppm) } & \multirow{2}{*}{$\operatorname{Re} \%$} & \multirow{2}{*}{ R.S.D\% } & \multicolumn{2}{|c|}{ Conc. of thymol (ppm) } & \multirow{2}{*}{$\operatorname{Re} \%$} & \multirow{2}{*}{ R.S.D\% } \\
\hline & Percent & Found & & & Percent & Found & & \\
\hline Fresh Burst wash mouth ADA, & 2.5 & 2.390 & 95.600 & 0.909 & 2.5 & 2.520 & 100.800 & 0.819 \\
\hline \multirow[t]{2}{*}{ American dental association } & 25 & 25.310 & 101.240 & 0.181 & 25 & 24.830 & 99.320 & 0.561 \\
\hline & 37.5 & 37.390 & 99.710 & 0.127 & 37.5 & 37.820 & 100.720 & 0.427 \\
\hline Cool mint wash mouth ADA, & 2.5 & 2.390 & 95.600 & 0.917 & 2.5 & 2.460 & 98.400 & 1.098 \\
\hline \multirow{2}{*}{ American dental association } & 25 & 25.050 & 100.20 & 0.173 & 25 & 24.910 & 99.640 & 0.570 \\
\hline & 37.5 & 37.340 & 99.580 & 0.128 & 37.5 & 37.891 & 101.042 & 0.133 \\
\hline Mouth and Dental wash Zak & 2.5 & 2.410 & 96.400 & 0.925 & 2.5 & 2.451 & 98.040 & 0.198 \\
\hline \multirow{2}{*}{ Egypt } & 25 & 24.940 & 99.760 & 0.184 & 25 & 25.340 & 101.360 & 0.358 \\
\hline & 37.5 & 37.290 & 99.440 & 0.128 & 37.5 & 37.620 & 100.320 & 0.274 \\
\hline Pure & 2.5 & 2.440 & 97.600 & 0.900 & 2.5 & 2.472 & 98.880 & 1.014 \\
\hline \multirow[t]{2}{*}{ thymol } & 25 & 25.360 & 101.440 & 0.181 & 25 & 24.870 & 99.480 & 0.482 \\
\hline & 37.5 & 37.440 & 99.840 & 0.127 & 37.5 & 37.555 & 100.146 & 0.344 \\
\hline F-value & & & & & 0.102 & & & \\
\hline t-value & & & & & 0.914 & & & \\
\hline
\end{tabular}

Table 7. Antibacterial effects of silver nanoparticles against Gram-negative and Gram-positive pathogenic bacteria

\begin{tabular}{|c|c|c|c|c|c|}
\hline Types of bacteria & Antibiotics & $\begin{array}{c}\text { Silver nitrate } \\
\text { (inhibition zone) }\end{array}$ & $\begin{array}{l}\text { Silver nanoparticles } \\
\text { (inhibition zone) }\end{array}$ & $\begin{array}{c}\text { Antibiotics } \\
\text { (inhibition zone) }\end{array}$ & $\begin{array}{l}\text { Antibiotics with } \\
\text { silver nanoparticles } \\
\text { (inhibition zone) }\end{array}$ \\
\hline Klebsiella pneumoniae & Thymol & 7 m.m & $12 \mathrm{~m} . \mathrm{m}$ & $11 \mathrm{~m} \cdot \mathrm{m}$ & $15 \mathrm{~m} . \mathrm{m}$ \\
\hline Escherichia coli & Thymol & $6 \mathrm{~m} . \mathrm{m}$ & 13.5 m.m & 13 m.m & 14 m.m \\
\hline Staphyllococcus aureus & Thymol & $6 \mathrm{~m} . \mathrm{m}$ & 8 m.m & 0 m.m & 9 m.m \\
\hline Enterococcus faecalis & Thymol & $5 \mathrm{~m} . \mathrm{m}$ & 6 m.m & 0 m.m & 7 m.m \\
\hline
\end{tabular}




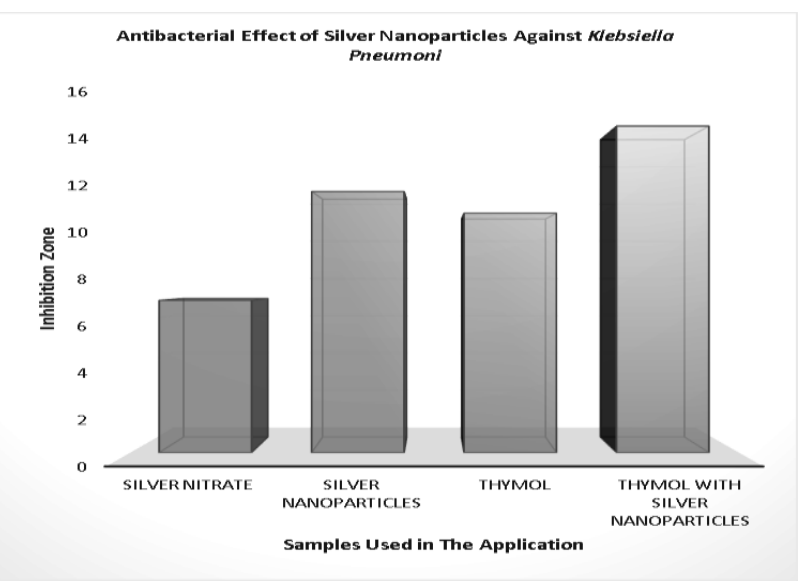

Figure 11. Effect of Antibacterial of Silver nanoparticles contra Klebsiella pneumonia

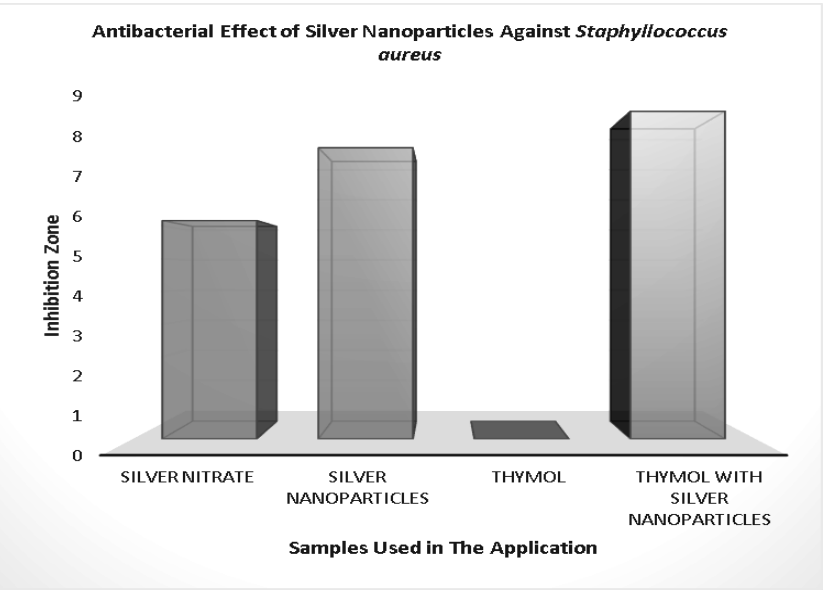

Figure 13. Effect of Antibacterial of Silver nanoparticles contra Staphyllococcus aureus

In conclusion, simple and rapid quantitative spectrophotometric method based on direct assessment of thymol formed both in its pure form and in pharmaceutical preparations, based on modified nanoparticles as color sensors by the interaction of thymol oxidation and reduction with silver nitrate. The suggested spectral method for estimating thymol produced high sensitivity, low detection, and a good linear range. Colored products are characterized by their high stability in the water medium, and this method has good accuracy and precision. The method does not necessarily require any model pretreatments or solvent extraction. The method was effective in estimating thymol in pharmaceutical preparations, and the results were in line with the original content. The statistical results $t, F$ test of the proposed spectral method compared to the standard method revealed no significant differences in the accuracy and reliability of the method, as well as the validity of the analytical application of this method. The prepared sample was applied to some bacteria, as well as its efficacy in reducing the bacteria wall's resistance was clear.

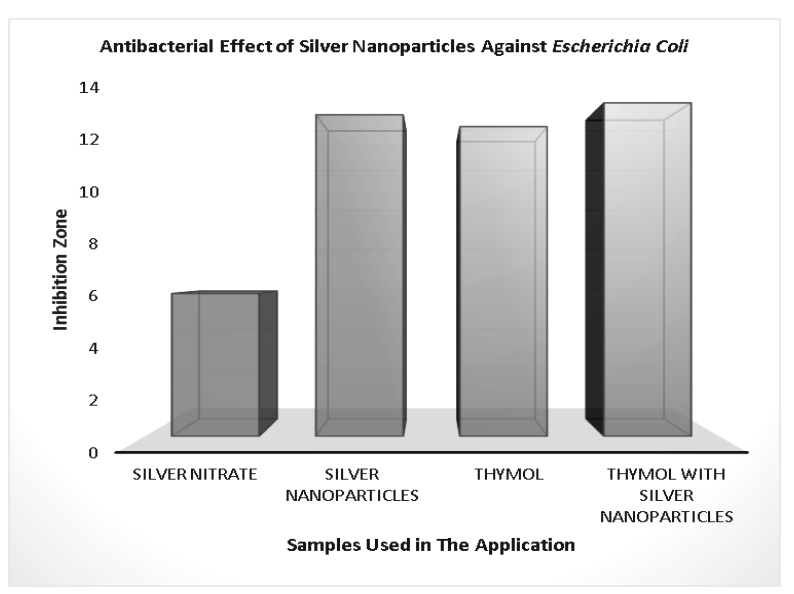

Figure 12. Effect of Antibacterial of Silver nanoparticles contra Escherichia coli

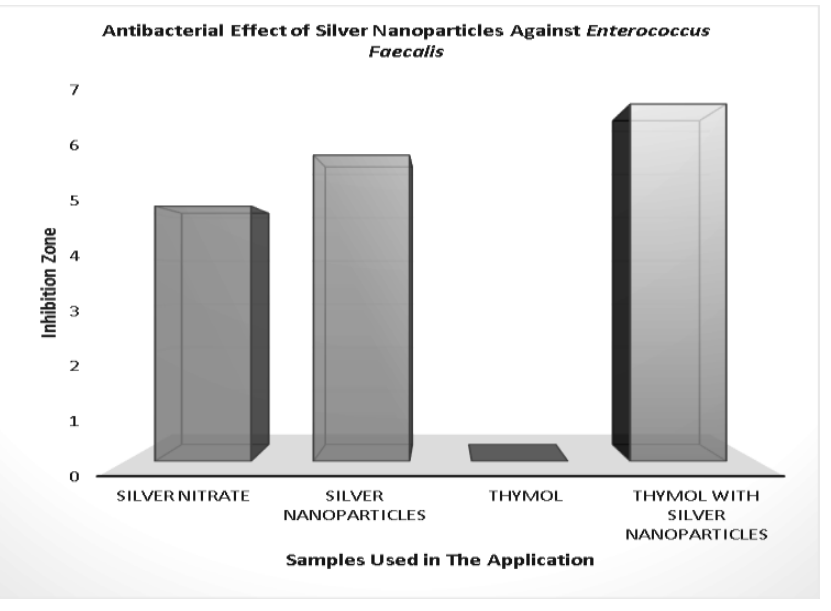

Figure 14. Effect of Antibacterial of Silver nanoparticles contra Enterococcus faecalis

\section{REFERENCES}

Aghamohseni B, Hassaninejad-Darzi SH, Asadollahi-Baboli M. 2019. A new sensitive voltammetric determination of thymol based on MnY nano zeolite modified carbon paste electrode using response surface methodology. Microchem J 145: 819-832. DOI: 10.1016/j.microc.2018.11.045.

Ahmed AK, Shahla JS. 2019. Determination of amoxicillin in pharmaceutical preparations by spectrophotometric and flow injection-activated chemiluminescence methods. Tikrit J Pure Sci 14: 63-79.

Alavi M, Naser K. 2019. Biosynthesis of Ag and Cu NPs by secondary metabolites of usnic acid and thymol with biological macromolecules aggregation and antibacterial activities against multi drug-resistant (MDR) bacteria. Int J Biol Macromol 128: 893-901. DOI: 10.1016/j.ijbiomac.2019.01.177.

Al-Ward HS, Al-Abachi MQ. 2012. Batch and flow-injection spectrophotometric determination of thymol using procaine hydrochloride as a new chromogenic reagent. Baghdad Sci J 9(2): 302-310. DOI: 10.21123/bsj.9.2.302-310.

Angelo T, Pires FQ, Gelfuso GM, da Silva JK, Gratieri T, Cunha-Filho M S. 2016. Development and validation of a selective HPLC-UV method for thymol determination in skin permeation experiments. $\mathbf{J}$ Chromatogr B Analyt Technol Biomed Life Sci 1022: 81-86. DOI: 10.1016/j.jchromb.2016.04.011

Bhosale RS, Hajare KY, Mulay B, Mujumdar S, Kothawade M. 2015. Biosynthesis, characterization and study of antimicrobial effect of 
silver nanoparticles by Actinomycetes spp. Int J Curr Microbiol Appl Sci 2: 144-151.

Christian GD. 2004. Analytical Chemistry, 6th ed. John Wiley and Sons, Inc.

Deepthi RS, Narasimha RG. 2013. Antimicrobial activity of mangrove plant Avicennia officinalis (Lam. Briqvet) on selected pathogens. Res J Pharm Biol Chem Sci 4: 335-341.

Dhahir SA, Hussein HJ. 2012. Spectrophotometric determination of thymol in pure and Listerine mouth washing. Tikrit J Pure Sci 17: $97-$ 102.

Fiori GML, Bonato PS, Pereira MPM, Contini SHT, Pereira AMS. 2013. Determination of thymol and carvacrol in plasma and milk of dairy cows using solid-phase microextraction. J Braz Chem Soc 24(5): 837846. DOI: $10.5935 / 0103-5053.20130109$.

Ganash AA 2019. Electrochemical properties and mechanistic study of the green synthesis of silver nanoparticles using Bardaqush extract solution. Mater Res Express 6: 065024. DOI: 10.1088/2053$1591 / \mathrm{ab} 0 \mathrm{~d} 40$.

Gao H, Cao W, Liang Y, Cheng N, Wang BN, Zheng JB. 2010 Determination of thymol and phenol in honey by LC with electrochemical detection. Chromatographia 72: 361-363. DOI: 10.1365/s10337-010-1628-4.

Geoprincy G, Saravanan P, Gandhi NN, Renganathan S. 2014. A novel approach for studying the combined antimicrobial effects of silver nanoparticles and antibiotics through agar overlayer method and disk diffusion method. Dig J Nanomater Biostructures 6: 1557-1565.

Gurunathan S, Han JW, Kwon DN, Kim JH. 2014. Enhanced antibacterial and anti-biofilm activities of silver nanoparticles against Gramnegative and Gram-positive bacteria. Nanoscale Res Lett 9(1): 1-17. DOI: $10.1186 / 1556-276 X-9-373$.

Hajimehdipoor H, Shekarchi M, Khanavi M, Adib N, Amri M. 2010. A validated high-performance liquid chromatography method for the analysis of thymol and carvacrol in Thymus vulgaris L. volatile oil. Pharmacogn Mag 6: 154-158. DOI: 10.4103/0973-1296.66927.

Harvey D. 2000. Modern Analytical Chemistry, 1st ed. McGraw-Hil Higher Education.

Hwang IS, Hwang JH, Choi H, Kim KJ, Lee DG. 2012. Synergistic effects between silver nanoparticles and antibiotics and the mechanisms involved. J Med Microbiol 61(12): 1719-1726. DOI 10.1099/jmm.0.047100-0.

Jiménez-Salcedo M, Tena MT. 2017. Determination of cinnamaldehyde, carvacrol and thymol in feedstuff additives by pressurized liquid extraction followed by gas chromatography-mass spectrometry. J Chromatogr A 1487 14-21. DOI: 10.1016/j.chroma.2017.01.042.
Kavitha R, Francisca P, Auxilia A. 2019. Biosynthesis, characterization and antibacterial effect of plant-mediated silver nanoparticles from Adenanthera pavoninal. JETIR 6: 2349-5162

MacFaddin JF. 2009. Biochemical Tests for Identification of Medical Bacteria. Williams and Wilkins, Philadelphia.

Meeran MFN, Javed H, Al Taee H, Azimullah S, Ojha SK. 2017. Pharmacological properties and molecular mechanisms of thymol: Prospects for its therapeutic potential and pharmaceutical development. Front Pharmacol 8: 1-34. DOI: 10.3389/fphar.2017.00380.

Moffat AC, Osselton MD, Widdop B, Watts J. 2011. Clarke's analysis of drugs and poisons, 4ed. Pharmaceutical Press, London.

Murray PR, Baron EJ, Pfaller MA, Tenover FC, Yolken HR. 1995. Manual of clinical microbiology, 6th Ed. ASM Press, Washington DC.

Nezhad MRH, Tashkhourian J, Khodaveisi J. 2010. Sensitive spectrophotometric detection of dopamine, levodopa and adrenaline using surface plasmon resonance band of silver nanoparticles. J Iran Chem Soc 7: S83-S91. DOI: 10.1007/BF03246187. DOI: 10.1007/BF03246187.

Nikparast Y, Mahsa S. 2018. Synergistic effect between phytosynthesized silver nanoparticles and ciprofloxacin antibiotic on some pathogenic bacterial strains. J Med Bacteriol 7: 36-43.

Olurinola PF. 1996. A laboratory manual of pharmaceutical microbiology. Idu, Abuja, Nigeria.

Ramalivhana JN, Obi CL, Samie A, Iweriebor BC, Uaboi-Egbenni P, Idiaghe JE, Momba MNB. 2014. Antibacterial activity of honey and medicinal plant extracts against Gram-negative microorganisms. Afr J Biotechnol 13: 616-625. DOI: 10.5897/AJB11.892.

Roosta M, Ghaedi M, Daneshfar A, Sahraei R. 2015. Ultrasound-assisted microextraction-nano material solid-phase dispersion for extraction and determination of thymol and carvacrol in pharmaceutical samples: Experimental design methodology. J Chromatogr B Biomed Appl 975: 34-39. DOI: 10.1016/j.jchromb.2014.10.035.

Tawa R, Shingo H. 1980. Differential kinetic determination of mixtures of aniline and its derivatives using n, n-dimethyl-p-phenylenediamine. Chem Pharm Bull 28(7): 2136-2143. DOI: 10.1248/cpb.28.2136.

Vu XH, Duong TTT, Pham TTH, Trinh DK, Nguyen XH, Dang VS. 2018. Synthesis and study of silver nanoparticles for antibacterial activity against Escherichia coli and Staphylococcus aureus. Adv Nat SciNanosci Nanotechnol 9(2): 025019. DOI: 10.1088/2043-6254/aac58f.

Ziyatdinova G, Ziganshina E, Cong PN, Budnikov H. 2017. Voltammetric determination of thymol in oregano using $\mathrm{CeO} 2$-modified electrode in Brij® 35 micellar medium. Food Anal Methods 10: 129-136. DOI: 10.1007/s12161-016-0562-y. 